\title{
Thoracoscopic Sympathicotomy for Treatment of Hyperhidrosis
}

\author{
Karamollah Toolabi ${ }^{1, *} ;$ Hamid Ahmadi ${ }^{1}$; Fezzeh Elyasinia ${ }^{1}$; Reza Parsaei ${ }^{1}$ \\ ${ }^{1}$ Surgery Department, Emam Khomeini Hospital, Tehran University of Medical Sciences, Tehran, IR Iran \\ *Corresponding author: Karamollah Toolabi, Surgery Department, Emam Khomeini Hospital, Tehran University of Medical Sciences, Tehran, IR Iran. Tel: +98-2188635269, Fax: \\ +98-2166581615, E-mail: tolabika@sina.tums.ac.ir \\ Received: April 21, 2014; Accepted: December 8, 2014
}

\begin{abstract}
Background: Approximately, 3\% of the world's population have hyperhidrosis, a situation in which excessive sweating occurs in response to the need to regulate body temperature. Endoscopic devices have been used for treatment of this disease through sympathicotomy. Objectives: The aim of this study was to assess the effectiveness and adverse effects of endoscopic sympathicotomy in treatment of hyperhidrosis.

Patients and Methods: We enrolled 41 patients in the study. Ganglion disconnection was performed at T2 - T3 level for patients with palmar hyperhidrosis and at T3-T4 level for patients with axillary hyperhidrosis. Patients were evaluated for successful response to surgical treatment, occurrence of reflex hyperhidrosis following surgery, and location of reflex hyperhidrosis at one week and at six months of surgery.

Results: After surgical treatment, $75.6 \%$ of patients reported complete response to treatment while $82.9 \%$ reported reflex hyperhidrosis after surgery. The frequency for moderate and severe sweating was $8.8 \%$ and $26.5 \%$, respectively.

Conclusions: Sympathicotomy technique can be used in the treatment of primary hyperhidrosis in patients who did not respond to nonsurgical treatments; however, the incidence of reflex hyperhidrosis is of concern following surgical treatment.
\end{abstract}

Keywords: Hyperhidrosis; Thoracoscopy; Ganglia

\section{Background}

Approximately 3\% of populations are affected by hyperhidrosis (1). It is characterized by extreme sweating in palms, axilla, feet, and face (2). It can be too troublesome to impair social life of patients and affect their quality of life (3). Since medical therapy does not yield satisfactory results, surgical sympathectomy has been widely used as a reliable treatment. Sympathectomy by removing second thoracic ganglion has been successful in controlling hyperhidrosis (4). Thoracoscopic sympathectomy has been used for a long time. It has less postoperation morbidity and better cosmetic result. Therefore, it has replaced open sympathectomy as treatment of choice for hyperhidrosis. Most important adverse effect of sympathectomy is reflex hyperhidrosis, which manifests by severe sweating in other parts of body. This complication is reported in $10 \%$ to $40 \%$ of patients after surgery $(5,6)$. An alternative surgery is cutting fiber between the sympathetic ganglions, which is named sympathicotomy. It is easier to perform and is reported to treat hyperhidrosis as successfully as conventional sympathectomy (7). More importantly, it is reported in some studies that sympathicotomy is associated with considerable lower rate of reflex hyperhidrosis.

\section{Objectives}

Since there is some controversy over outcome and complications of sympathicotomy in literature, we designed this study to compare two surgical methods in treatment of hyperhidrosis.

\section{Patients and Methods}

We recruited 41 patients who were referred to our centers with the diagnosis of with hyperhidrosis and failed medical therapy from March 2012 to October 2013. The informed consent was obtained from patient after explaining study aim and design to them. Surgery was performed at either Imam Khomeini Hospital, Tehran, Iran, or Erfan Hospital, Tehran, Iran. One surgeon experienced in minimally invasive surgery performed all surgeries.

\subsection{Surgical Technique}

All patients underwent bilateral sympathicotomy under general anesthesia. Patient was positioned supine with his/her arms abducted by 90 degrees. A 3-mm port 
was inserted in the fourth intercostal space at anterior axillary line for camera and a 3-mm port was inserted in fifth intercostals space at midaxillary line for electrocautery hook. Connection between T2 and T3 ganglions was severed with electrocautery for palmar hyperhidrosis and connection between T3 and T4 ganglions was severed for axillary hyperhidrosis. For combined hyperhidrosis sympathicotomy at T2-T3 and T3 - T4 level was performed. Patients were evaluated in clinic one week after surgery and by telephone inquiry six months after surgery. For evaluating hyperhidrosis, patients were asked to describe their perspiration as scaled variables as follows: 1 , normal; 2 , sometimes having moisture; 3 , often having moisture; 4, sometimes dripping; and 5, often dripping. Reflex perspiration was evaluated by description of patients in a scale ranging from zero through 10, where zero stood for "No perspiration" and 10 for "severe bothersome perspiration". Site of reflex perspiration was also determined.

\section{Results}

Patients had no intraoperative or postoperative complication. From 41 patients recruited into study, 13 (32\%) were male and 28 (68\%) were female with the mean age of 27.7 years (range, 14 - 44 years). Palmar hyperhidrosis was present in 12 patients (29\%) while16 patients (39\%) complained of combined palmar and axillary hyperhidrosis. In four patients (10\%), hyperhidrosis was in axilla only. Five patients $(12 \%)$ had hyperhidrosis in palmar, plantar, and axilla and 3 (7\%) had hyperhidrosis in palmar and plantar region. Response to surgery was complete in 31 patients (76\%) who reported no perspiration in region of complaint. Nine patients (22\%) reported decrease in perspiration while there was still some degree of moisture. one patient was not satisfied with surgery and did not show any decrease in perspiration. Response to surgery is illustrated in Table 1. There was no association between age or sex and response to treatment. Reflex hyperhidrosis was seen in 34 patients (83\%). In 14 patients (34\%), reflex hyperhidrosis was present in lumbar region, in 7 (17\%) in lower abdomen, and in $8(19 \%)$ in both lower abdomen and lumbar region. There was no recurrence in our follow-up at six month of surgery.

\begin{tabular}{lc}
\hline Table 1. Hyperhidrosis Location in Patients & \\
\hline Hyperhidrosis Location & Frequency, \% \\
\hline Palmar & $12(29.3)$ \\
Palmar and Plantar & $3(7.3)$ \\
Palmar and Axillae & $16(39.0)$ \\
Palmar, Plantar, and Axilla & $5(12.2)$ \\
Palmar and Axilla, and Lower Limbs & $1(2.4)$ \\
Axilla & $4(9.8)$ \\
Total & $41(100)$ \\
\hline
\end{tabular}

\section{Discussion}

Limited surgical manipulation of sympathetic ganglion has been adopted for treatment of hyperhidrosis. Most studies found that sympathicotomy is a reliable method with acceptable results in treatment of hyperhidrosis (8-10). Our study showed that sympathicotomy is quite effective in treating hyperhidrosis in all regions and is associated with excellent patient satisfaction (Table 2). In our six months follow-up period, we found no recurrences. Although some studies have followed patients for longer periods (11), failure of surgery in reducing perspiration is expected to be evident in six months of surgery (12-14). Reflex hyperhidrosis is an important complication of surgery because sweating is the problem that make patient to undergo surgery. Its occurrence is reported to range from $9 \%$ to $100 \%$ of patients (11). There is also debate pertaining the association between surgical procedure and incidence of reflex hyperhidrosis. Atkinson et al. reported that sympathicotomy is associated with significant lower rate of reflex hyperhidrosis (7). Some hypothesis might explain this finding. First, it is hypothesized that lesser manipulation of sympathetic chain leads to smaller area of anhidrosis that in turn, results in less severe reflex mechanisms (15). Second, it is probable that resection of ganglion causes cellular death of certain neurons in spinal cord and resultant reorganization may lead to increased sympathetic tone due to short-circuit pathways $(7,16,17)$.

Results of Atkinson et al. (7) was not reproduced in all studies and some authors did not find any significant difference in rate of reflex hyperhidrosis in different surgical procedures (18). It is suggested that excessive manipulation, whether sympathectomy or sympathicotomy, can damage sympathetic ganglia and result in reflex hyperhidrosis (19). Meta-analysis of different studies can be helpful in elucidating role of surgical methods in incidence of reflex hyperhidrosis. In our study, rate of reflex hyperhidrosis was relatively high (83\%). Unfortunately, because we did not perform sympathectomy, comparing two methods in this regard was not possible. Our study had some limitations. Perspiration was assessed subjectively by our patient. Precise quantitative measures such as Quinizarin sweat test (20) or Mayo Clinic thermoregulatory sweat test (21) can be most helpful in determining response to treatment. However, it may not be a major flaw in assessing success rate of surgery because patient subjective satisfaction is endpoint of treating hyperhidrosis.

Sympathicotomy seems to be an effective alternative to sympathectomy in treating hyperhidrosis. This method's benefits are lesser trauma and more safety because of sparing sympathetic ganglions. In addition, patients would be discharged from hospital earlier. Whether it is associated with fewer complications in compare to sympathectomy, especially in occurrence of reflex hyperhidrosis, remain to be studied by further trials and metaanalyses. 
Table 2. Severity of Hyperhidrosis in Patients One Week After Surgery

\begin{tabular}{lc}
\hline Sweating Severity Scale & No.(\%) \\
\hline $\mathbf{1}$ & $31(75)$ \\
$\mathbf{2}$ & $5(12)$ \\
$\mathbf{3}$ & $3(7)$ \\
$\mathbf{4}$ & $1(2)$ \\
$\mathbf{5}$ & $1(2)$ \\
\hline
\end{tabular}

\section{Acknowledgements}

The authors greatly acknowledge Dr. Alborz Sherafati for his help.

\section{Authors' Contributions}

Study concept, study supervision, and design and administrative, technical, and material support: Karamollah Toolabi; Acquisition of data and analysis and interpretation of data: Hamid Ahmadi; Drafting the manuscript: Hamid Ahmadi and Fezzeh Elyasinia; Critical revision of the manuscript for important intellectual content: Karamollah Toolabi, Fezzeh Eliasinia, and Reza Parsaei; Statistical analysis: Hamid Ahmadi, Reza Parsaei.

\section{References}

1. Bechara FG, Gambichler T, Bader A, Sand M, Altmeyer P, Hoffmann K. Assessment of quality of life in patients with primary axillary hyperhidrosis before and after suction-curettage. $\mathrm{J} \mathrm{Am}$ Acad Dermatol. 2007;57(2):207-12.

2. Cerfolio RJ, De Campos JR, Bryant AS, Connery CP, Miller DL, DeCamp MM, et al. The Society of Thoracic Surgeons expert consensus for the surgical treatment of hyperhidrosis. Ann Thorac Surg. 2011;91(5):1642-8.

3. de Campos JR, Kauffman P, Werebe Ede C, Andrade Filho LO, Kusniek S, Wolosker N, et al. Quality of life, before and after thoracic sympathectomy: report on 378 operated patients. Ann Thorac Surg. 2003;76(3):886-91.

4. Kux E. The endoscopic approach to the vegetative nervous system and its therapeutic possibilities; especially in duodenal ulcer, angina pectoris, hypertension and diabetes. Dis Chest. 1951;20(2):139-47.

5. Lai YT, Yang LH, Chio CC, Chen HH. Complications in patients with palmar hyperhidrosis treated with transthoracic endoscopic sympathectomy. Neurosurgery. 1997;41(1):110-3.

6. Han PP, Gottfried ON, Kenny KJ, Dickman CA. Biportal thoracoscopic sympathectomy: surgical techniques and clinical results for the treatment of hyperhidrosis. Neurosurgery. 2002;50(2):306-11.

7. Atkinson JL, Fealey RD. Sympathotomy instead of sympathectomy for palmar hyperhidrosis: minimizing postoperative compensatory hyperhidrosis. Mayo Clin Proc. 2003;78(2):167-72.

8. Kim JB, Park CK, Kum DY. The effect of thoracoscopic sympathicotomy at the fourth rib (r4) for the treatment of palmar and axillary hyperhidrosis. Korean J Thorac Cardiovasc Surg. 2011;44(2):154-8.

9. Leseche G, Castier Y, Thabut G, Petit MD, Combes M, Cerceau O, et al. Endoscopic transthoracic sympathectomy for upper limb hyperhidrosis: limited sympathectomy does not reduce postoperative compensatory sweating. J Vasc Surg. 2003;37(1):124-8.

10. Munia MA, Wolosker N, Kauffman P, de Campos JR, Puech-Leao P. A randomized trial of T3-T4 versus T4 sympathectomy for isolated axillary hyperhidrosis. J Vasc Surg. 2007;45(1):130-3.

11. Mohebbi HA, Mehrvarz S, Manoochehry S. Thoracoscopic Sympathicotomy vs Sympathectomy in Primary Hyperhidrosis. Trauma Mon. 2012;17(2):291-5.

12. Cohen Z, Levi I, Pinsk I, Mares AJ. Thoracoscopic upper thoracic sympathectomy for primary palmar hyperhidrosis--the combined paediatric, adolescents and adult experience. Eur J Surg Suppl.1998(580):5-8.

13. Hashmonai M, Kopelman D, Ehrenreich M, Assala A, editors. The learning curve of thoracoscopic sympathectomy.; 6th World Congress of Endoscopic Surgery..1998; Rome, Italy.

14. Jeganathan R, Jordan S, Jones M, Grant S, Diamond O, McManus K, et al. Bilateral thoracoscopic sympathectomy: results and longterm follow-up. Interact Cardiovasc Thorac Surg. 2008;7(1):67-70.

15. O'Riordain DS, Maher M, Waldron DJ, O'Donovan B, Brady MP. Limiting the anatomic extent of upper thoracic sympathectomy for primary palmar hyperhidrosis. Surg Gynecol Obstet. 1993;176(2):151-4.

16. Kirgis HD, Kuntz A. Inconstant sympathetic neural pathways: Their relation to sympathetic denervation of the upper extremity. Arch Surg. 1942;44(1):95-102.

17. Kuntz A, Dillon JB. Preganglionic components of the first thoracic nerve: Their role in the sympathetic innervation of the upper extremity. Arch Surg. 1942;44(4):772-8.

18. Rodriguez PM, Freixinet JL, Hussein M, Valencia JM, Gil RM, Herrero J, et al. Side effects, complications and outcome of thoracoscopic sympathectomy for palmar and axillary hyperhidrosis in 406 patients. Eur J Cardiothorac Surg. 2008;34(3):514-9.

19. Bonjer HJ, Hamming JF, du Bois N, van Urk H. Advantages of limited thoracoscopic sympathectomy. Surg Endosc.1996;10(7):721-3.

20. Guttmann L. The management of the quinizarin sweat test (Q.S.T.). Postgrad Med J.1947;23(262):353-66.

21. Fealey RD, Low PA, Thomas JE. Thermoregulatory sweating abnormalities in diabetes mellitus. Mayo Clin Proc.1989;64(6):617-28. 